\title{
Hip involvement in early rheumatoid arthritis
}

\author{
Kerstin Eberhardt, Eva Fex, Kjell Johnsson, Pierre Geborek
}

\begin{abstract}
Objective-To study early hip involvement in rheumatoid arthritis (RA) and to evaluate the usefulness of ultrasonography in the detection of hip joint synovitis in RA.
\end{abstract}

Methods-Study I: The number of hip joint replacements was recorded in a cohort of 113 patients with RA of at least five years disease duration followed from an early stage. Study II: Ultrasonography was evaluated as a method to identify hip joint synovitis in 76 patients with $R A$ of shorter disease duration, by relating it to radiograms and clinical findings.

Results-Study I: Twenty one hip joint replacements were performed in 15 of the 113 patients. The median disease duration at the time of first arthroplasty was 48 (range 10-76) months; the annual incidence was approximately constant between two and six years. High disease activity at the start of the study was predictive of requirement for hip prosthesis. Study II: Hip ultrasonography was pathological in 13 of the 76 patients studied, bilaterally in nine. Hip joint synovitis could not be confirmed on clinical grounds only as seven of the patients with positive ultrasonographic findings were asymptomatic, and the remaining six patients had only mild symptoms of hip involvement. Also, six of the 63 patients with normal ultrasonography had mild symptoms. There was no difference regarding demographic, clinical, and laboratory findings in patients with and without hip synovitis.

Conclusions-Early hip joint destruction giving symptoms mostly at a very late stage is frequent in RA. Ultrasonography rather than signs or symptoms could identify patients with hip joint involvement and provide a rationale for early treatment.

(Ann Rheum Dis 1995; 54: 45-48)

Department of

Rheumatology,

Lund University

Hospital,

S-221 85 Lund, Sweden

K Eberhardt

E Fex

P Geborek

Department of

Diagnostic Radiology

K Johnsson

Correspondence to:

Dr Eberhardt.

Accepted for publication

2 September 1994 $15 \%$ of the hip joints in 64 patients RA showed impaired function as evaluated with the Signals Of Functional Impairment (SOFI) index after one year's disease duration.
After five years of follow up the frequency had increased to $28 \%$. The hip joint involvement developed rapidly, leading to joint destruction and joint replacement in $13 \%$ of the patients during the five year observation period ( $\mathrm{K}$ Eberhardt, E Fex, in preparation). The patients in that study participated in a prospective early RA study, allowing for inclusion of all degrees of disease severity. Roberts $e t \mathrm{al}^{3}$ performed a retrospective investigation of a selected patient group with persistent active disease for five years and found hip joint involvement in $26 \%$ within six months after onset.

The high frequency of early hip joint destruction in our patient cohort suggested a need for a more active treatment approach. However, synovitis of the hip joint is difficult to assess on clinical examination, and ultrasonography has recently been introduced as a method to detect hip joint synovitis. ${ }^{4}$ This study was undertaken to evaluate if this method allowed earlier objective detection of both symptomatic and asymptomatic hip joint synovitis in a group of patients with early RA. We also extended the previous observation of early hip joint replacement in RA to a larger group of patients followed for five years.

\section{Patients and methods}

The patients were participating in a prospective study of the course and outcome of RA. ${ }^{2}$ Criteria for inclusion were definite $\mathrm{RA}^{5}$ with a disease duration of 24 months or less in patients aged 18 years or more. A total of 180 patients were enrolled during the years 1985-9. Most patients were referred from primary care units by a system which allowed for inclusion of a wide spectrum of disease severity and did not encourage any selection. The patients were followed with standardised clinical and laboratory assessments every six months. The amount of joint inflammation was rated by an active joint count. Fifty peripheral joints were evaluated and an active joint was defined as swollen, tender, or painful on motion. Pain and patients' global assessment of disease activity were estimated on visual analogue scales. Pain rating was performed according to Fries et al. ${ }^{6}$ Disease activity was assessed on a $10 \mathrm{~cm}$ scale and the distance in $\mathrm{mm}$ from the left side of the scale to the patient's mark was multiplied by $0 \cdot 3$, giving a range of $0-3$. Disability was assessed with a validated Swedish version of the Stanford Health Assessment Questionnaire (HAQ) disability index. ${ }^{7}$ The range of motion of the hip joint was evaluated with the patient 


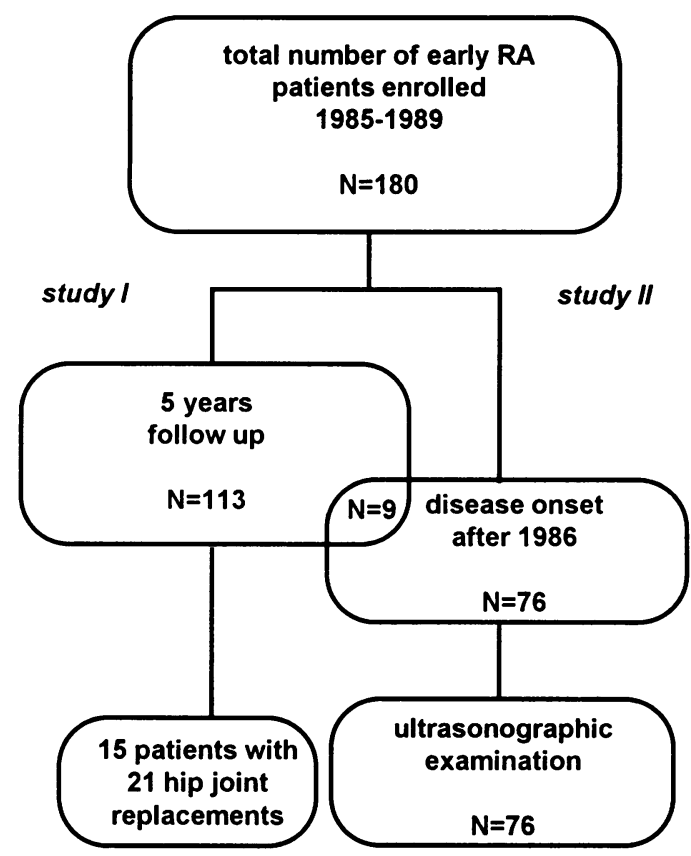

Figure 1 Schematic presentation of the patients enrolled in the early rheumatoid arthritis study.

lying supine, by internal and external rotation with the knee and hip flexed $90^{\circ}$.

Figure 1 shows the different groups of patients from the cohort investigated. A total of 113 have been followed for at least five years.

In study I the frequency of hip joint replacements performed in these patients during the period of observation was investigated. No previous hip radiograms were available, but there was no clinical evidence of pre-existing osteoarthritis of the hip.

In the second part of the investigation (study II) ultrasonography was performed in all 76 patients within the early RA cohort with disease onset January 1987 and later. There were 26 men and 50 women with a median age of 53.5 (range 29-83) years and median disease duration of $52(23-72)$ months at the time of ultrasonography. Seventy eight per cent were seropositive. Sixty two patients were

Table 1 Clinical and laboratory findings in 76 patients with rheumatoid arthritis at the time of the ultrasonic examination

\begin{tabular}{lccc}
\hline & $\begin{array}{c}\text { Positive ultrasonography } \\
(n=13)\end{array}$ & $\begin{array}{l}\text { Negative ultrasonography } \\
(n=63)\end{array}$ & $p$ \\
\hline Disease duration (months) & $35(23-65)$ & $56(27-72)$ & $<0 \cdot 001$ \\
Active joint count $(0-50)$ & $4(1-6)$ & $4(1-5)$ & $\mathrm{NS}$ \\
ESR (mm/1st h) & $22(13-44)$ & $29(13-46)$ & $\mathrm{NS}$ \\
HAQ $(0-3)$ & $1 \cdot 1(0 \cdot 3-1 \cdot 4)$ & $1 \cdot 1(0 \cdot 5-1 \cdot 5)$ & $\mathrm{NS}$ \\
Pain (0-3) & $0 \cdot 7(0 \cdot 5-1 \cdot 8)$ & $1 \cdot 1(0 \cdot 5-2)$ & $\mathrm{NS}$ \\
Patients' global assessment (0-3) & $1 \cdot 5(1-1 \cdot 6)$ & $1 \cdot 5(0 \cdot 8-1 \cdot 7)$ & $\mathrm{NS}$ \\
Morning stiffness (min) & $45(0-60)$ & $30(0-90)$ & \\
\hline
\end{tabular}

Median values (range) and level of significance $(p)$. NS $=$ Not significant; ESR $=$ erythrocyte sedimentation rate; $\mathrm{HAQ}=$ health assessment questionnaire.

Table 2 Clinical and laboratory findings at study entry of the 113 patients followed for at least five years. The cohort is grouped according to later hip joint replacement or not

\begin{tabular}{lllc}
\hline & $\begin{array}{l}\text { Non-operated group } \\
(n=98)\end{array}$ & $\begin{array}{l}\text { Hip replacement group } \\
(n=15)\end{array}$ & $p$ \\
\hline Age at disease onset $(\mathrm{yr})$ & $52(18-78)$ & $51(26-68)$ & $\mathrm{NS}$ \\
Male sex $(\%)$ & 31 & 53 & $\mathrm{NS}$ \\
Rheumatoid factor prevalence $(\%)$ & 60 & 73 & $\mathrm{NS}$ \\
ESR & $26(2-116)$ & $73(23-115)$ & $<0 \cdot 001$ \\
Active joint count & $6(1-26)$ & $12(2-20)$ & $<0 \cdot 05$ \\
\hline
\end{tabular}

Median values (range) or number, with level of significance (p). NS $=$ Not significant ESR = erythrocyte sedimentation rate. treated with NSAIDs, 12 with low doses of oral corticosteroids ( $\leqslant 7.5 \mathrm{mg}$ prednisolone), and 35 with various disease modifying antiinflammatory drugs, mostly chloroquine or penicillamine. Eight patients were in functional class (FC) I, 67 in FC II, and one in FC III according to Steinbrocker et al. ${ }^{8}$ Table 1 shows the clinical and laboratory findings at the time of hip ultrasonography, grouped according to positive or negative results from ultrasonography.

The patients were investigated either at the time of an annual routine radiographic examination of hands and feet, or when reporting symptoms from the hip region, which were actively elicited. Ultrasonography was performed from the anterior aspect of both hip joints using a Toshiba Sonolayer SSA-270A unit with a $7.5 \mathrm{MHz}$ linear transducer PLE $705 \mathrm{~F}$ or a 3.75 MHz sector scanner PVF $357 \mathrm{MT}$. The probe was positioned parallel to the femoral neck. The capsular height was measured from the cortex of the femoral neck to the outer layer of the capsule. The ultrasonic examination was considered pathological when the capsular height was $7 \mathrm{~mm}$ or greater. ${ }^{9}$ Fluid or synovial thickening that caused bulging of the capsule was also considered a pathological sign, irrespective of capsular height. The ultrasonographer was unaware of the clinical findings.

If ultrasonography was positive, radiographic examination of the hips was also performed. The radiographic changes were assessed by the method of Larsen. ${ }^{10}$

\section{Statistical analyses}

Differences between groups were assessed with the Mann-Whitney test for unpaired data. The $\chi^{2}$ test was applied for discrete data. The level of significance was set at 0.05 . Life table analysis was performed with the software from SPSS.

\section{Results}

STUDY I

In the 113 patients followed for at least five years, 21 hip joint replacements were performed in 15 patients with a median age of 54.5 (range 26-66) years at the time of first arthroplasty. Table 2 summarises the clinical and laboratory findings at study entry. The median disease duration at first joint replacement was 48 (10-76) months. Figure 2 shows the probability of receiving a hip joint implant in relation to disease duration in this cohort of RA patients. The incidence was relatively constant from approximatley two years of disease duration and the prevalence reached $13 \%$ by six years of disease duration. Numbers are more uncertain above this level because of the limited number of observations. The median duration of severe hip joint symptoms before radiographic confirmation of joint destruction was 3 (1-14) months. Only one of the patients had a disease onset after January 1987. Patients who eventually received a hip joint replacement had greater disease activity when entering the study (table 2). 


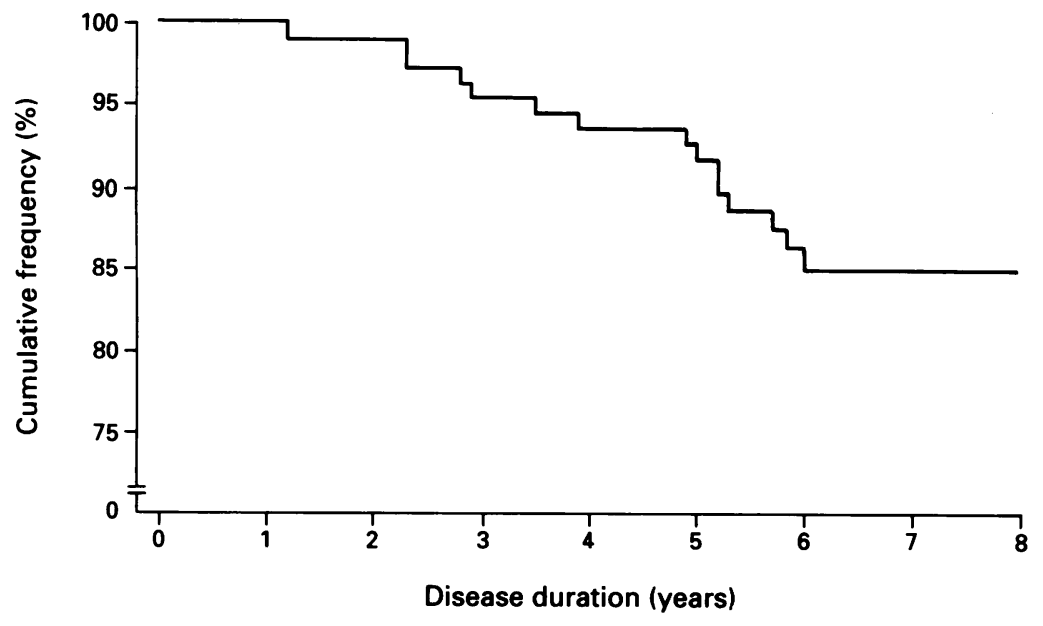

Figure 2 Life table analysis of the risk of having hip joint replacement surgery in relation to disease duration: cumulative frequency of patients not submitted to hip joint arthroplasty. The original cohort represents the 113 rheumatoid arthritis patients followed for at least five years. After six years of disease duration, $15 \%$ had been operated on. The curve is less reliable after six years of disease duration because of the diminished number at risk.

\section{STUDY II}

Of the 76 patients participating in the ultrasonography study, 13 had a positive ultrasonic examination, nine with bilateral findings (table 3). Synovial thickening and bulging was detected in 16 hips and fluid in nine. As an example, figure 3 shows the examination for patient No 6. Four of the patients with a

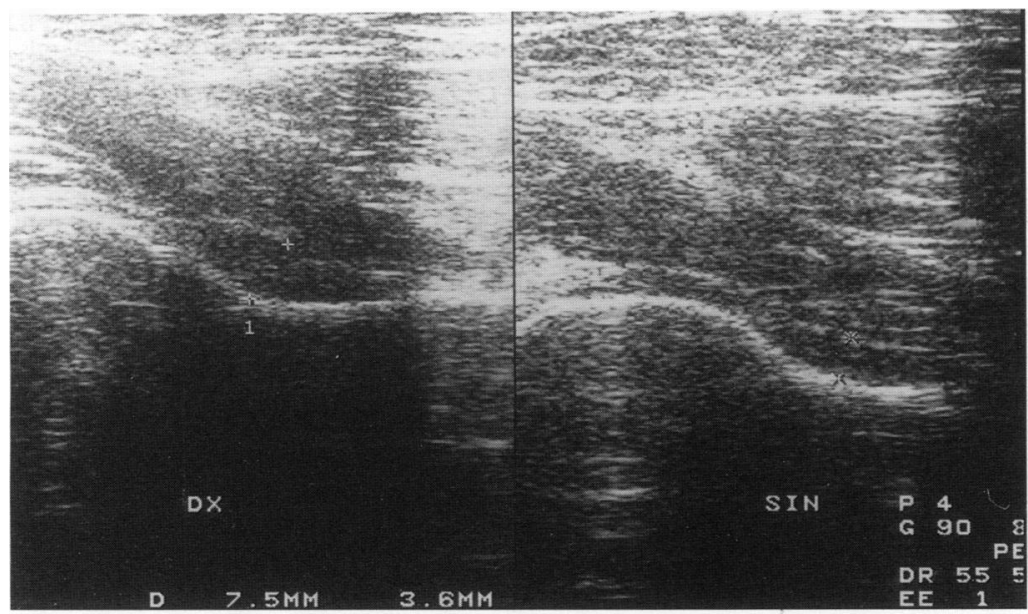

Figure 3 Ultrasonography of right and left hips in patient No 6. There is a minor effusion in the right hip, where the joint capsule is slightly displaced anteriorly. Capsular measurement is $7.5 \mathrm{~mm}$ on right side and $3.5 \mathrm{~mm}$ on left side. positive ultrasonic examination had neither signs nor symptoms of hip involvement, and were detected at routine annual radiographic examination. The remaining nine were examined because of symptoms or signs of hip involvement (four had symptoms and signs, two symptoms only, and three signs only). Signs of hip involvement mostly denoted impaired internal rotation. Symptoms and signs were mild in all cases.

Four of the 13 patients with positive ultrasonography had unequivocal radiographic changes (Larsen grade 2 or more). Only one of these four patients had symptoms and signs of hip joint involvement.

Of the 63 patients with a negative ultrasonography, six were referred for symptoms or signs of hip involvement, while the rest were examined at the routine annual radiographic examination.

Patients with a positive ultrasonic examination had a shorter disease duration and less pain, but were otherwise similar to the patients with a negative examination (table 1 ). There were no differences between the two groups regarding age, gender, seropositivity, or pharmacological treatment.

\section{Discussion}

It was possible to use the frequency of hip joint replacements as a measure of severe hip joint involvement in this study because decisions to perform surgery could be effectuated without delay. The main indication for replacement, which remained unchanged throughout the study, was severe pain in a joint for which there was radiological evidence of destruction. Severe hip joint involvement was more prevalent and occurred earlier than previously reported. Corbett $e t$ al ${ }^{11}$ found that only four hip joint replacements had been performed over 15 years in the 64 surviving patients of the Middlesex early RA study, but this may in part reflect poorer availability of joint replacements. A Finnish prospective study concluded that rheumatologists have as long as eight years to treat a patient in order to prevent hip involvement; ${ }^{12}$ they found a $3 \%$ incidence of severe radiographic hip joint destruction after eight years. Based on our findings, the time interval should be substantially shortened, to two years

Table 3 Clinical, ultrasonic and radiographic findings in 13 patients with a positive ultrasonic examination. The capsular height was considered normal when less than $7 \mathrm{~mm}$, unless there was bulging of the capsule (patient No 5)

\begin{tabular}{|c|c|c|c|c|c|c|c|c|}
\hline \multirow[t]{3}{*}{ Patient No } & \multicolumn{6}{|c|}{ Ultrasonography } & \multirow{2}{*}{\multicolumn{2}{|c|}{$\frac{\text { Radiology }}{\text { Larson grade }}$}} \\
\hline & \multicolumn{2}{|c|}{ Synovial hypertrophy } & \multicolumn{2}{|l|}{ Fluid } & \multicolumn{2}{|c|}{ Caps. height (mm) } & & \\
\hline & Right & Left & Right & Left & Right & Left & Right & Left \\
\hline 1 & - & - & + & + & 12 & 11 & 0 & 3 \\
\hline 2 & + & + & - & - & $8 \cdot 5$ & $7 \cdot 5$ & 0 & 0 \\
\hline 3 & + & + & - & - & 9 & 10 & 0 & 0 \\
\hline 4 & - & - & + & + & 12 & $8 \cdot 5$ & 1 & 2 \\
\hline 5 & + & + & - & - & 6 & 5 & 0 & 1 \\
\hline 6 & - & - & + & - & $7 \cdot 5$ & 3.5 & 0 & 0 \\
\hline 7 & - & - & - & + & 4 & 8 & 0 & 2 \\
\hline 8 & + & - & - & - & 8 & 5 & 0 & 0 \\
\hline 9 & + & + & - & - & $9 \cdot 5$ & 7 & 1 & 0 \\
\hline 10 & - & + & - & - & 4 & 8 & 0 & 0 \\
\hline 11 & + & + & + & - & 13 & 7 & 2 & 1 \\
\hline 12 & + & + & + & - & 12 & 8 & 1 & 1 \\
\hline 13 & + & + & + & - & 10 & 7 & 0 & 0 \\
\hline
\end{tabular}


at most (fig 2). Demographic or genetic factors may contribute to this discrepancy.

Ultrasonic evidence of hip synovitis was found in $17 \%$ of subjects. Those with synovitis had a median disease duration of three years, confirming that hip joint involvement may be a rather early event. Apart from the shorter disease duration, we found no differences regarding demographic, clinical or laboratory findings between patients with and without hip synovitis. This is in contrast to a previous ultrasonic investigation reporting longer disease duration (mean 9.4 years) and a greater frequency of rheumatoid factor negativity in patients with hip synovitis. ${ }^{13}$ The shorter disease duration that we found in the group with hip synovitis is probably explained by our active search for hip joint involvement and subsequently early ultrasonic examination.

Interestingly, seven of the 13 patients with a positive ultrasonic examination had no symptoms at all and the remaining patients had only mild symptoms, making a treatment intervention very doubtful in a normal clinical setting, but four were found to have radiographic signs of active hip joint destruction. In addition, six patients with symptoms or signs were normal upon ultrasonic examination, illustrating the difficulties of certifying hip synovitis on clinical grounds alone. The follow up period in the patients examined by ultrasonography is at present too short to permit any conclusions of the predictive value regarding late hip joint destruction.

The mild symptoms which we actively elicited are in contrast to the severe pain in the very late stages of destruction. The patients with hip joint replacement had a median duration of severe symptoms of only three months before radiographic confirmation of severe joint destruction.

There was a striking difference between destructive hip and knee joint involvement at this stage of the disease. Only one knee joint replacement had to be performed among the 113 patients with at least five years of follow up, but detectable knee joint synovitis was common, occurring in more than $50 \%$ of the patients. However, this apparently did not lead to the same rapid destruction of the knee joint. A contributing factor to this might be that knee joint involvement, in contrast to hip joint involvement, is easy to detect, and to treat by intra-articular glucocorticoid injections.

In conclusion, hip involvement may occur early and be rapidly progressive in RA patients. Ultrasonography is a useful tool to detect hip joint synovitis in patients with no or mild symptoms and can provide a rationale for intervention with intra-articular steroids or more aggressive pharmacotherapy at an early stage. This study was supported by Riksförbundet mot Reumatism, Kocks Stiftelse, Medicinska fakulteten vid Lunds Universitet, A-G Crafoords Fond, Lunds Sjukvårdsdistrikts
Donationsfonder, Konung Gustaf V:s 80-årsfond, and Alfred Österlunds Stiftelse.

Fleming A, Crown J M, Corbett $M$. Early rheumatoid arthritis. I. Onset. Ann Rheum Dis 1976; 35: 357-60.

2 Eberhardt K B, Rydgren L C, Pettersson H, Wollheim F A Early rheumatoid arthritis-Onset, course and prognosis over 2 years. Rheumatol Int 1990; 10: 135-42.

3 Roberts W N, Daltroy L H, Anderson R J. Stability of normal joint findings in persistent classic rheumatoid normal joint findings in persistent class

4 Koski J M, Anttila $P$, Hämäläinen $M$, Isomäki $H$. Hip join ultrasonography: correlation with intraarticular effusion ultrasonography: correlation with intraarticular

5 Ropes M W, Bennet G A, Cobb S, Jacox R, Jessar R A. Diagnostic criteria for rheumatoid arthritis. Ann Rheum Dis 1959; 18: 49-53.

6 Fries J F, Spitz P, Kraines R K, Holman H R. Measurement of patients outcome in arthritis. Arthritis Rheum 1980; 23: $137-45$

7 Ekdahl C, Eberhardt K, Andersson S I, Svensson B. Assessing disability in patients with rheumatoid arthritis. Scand $\mathcal{F}$ Rheumatol 1988; 17: 263-71.

8 Steinbrocker O, Traeger C H, Batterman R C. Therapeutic criteria in reumatoid arthritis. $¥ A M A 1949 ; 140: 659-62$. Koski J M, Antila P J, Isomäki H A. Ultrasonography of the adult hip joint. Scand $\mathcal{f}$ Rheumatol 1989; 18: 113-7.

10 Larsen A, Dale K, Eek M. Radiographic evaluation of arsen $A$, Dale $K$, Eek $M$. Radiographic evaluation of
rheumatoid arthritis and related conditions by standard reference films. Acta Radiol Diagnosis 1977; 18: 481-91.

11 Corbett M, Dalton S, Young A, Silman A, Shipley M Factors predicting death, survival and functional outcome in a prospective study of early rheumatoid disease over fifteen years. Br $\mathcal{F}$ Rheumatol 1993; 32: 717-23.

12 Lehtimäki M Y, Kaarela K, Hämäläinen M M J. Incidence of hip involvement and need for total hip replacement in rheumatoid arthritis. Scand 7 Rheumatol 1986; 15: 387-91.

13 Koski J M. Ultrasonographic evidence of hip synovitis in patients with rheumatoid arthritis. Scand $\mathcal{f}$ Rheumatol 1989; 18: $127-31$. 